\title{
Optimisation of the rational proportion of intelligent technologies application in service organisations
}

\section{Anton IVASCHENKOํㅗㄹ Alfiya R. DIYAZITDINOVA², Tatiyana NIKIFOROVA ${ }^{1}$}

${ }^{1}$ Samara State Technical University, Samara, Russia, anton.ivashenko@gmail.com, kolesnikova.t.v.163@gmail.com

${ }^{2}$ Povolzhskiy State University of Telecommunications and Informatics, Samara, Russia, dijazitdinova@mail.ru

Background and Purpose: The growing role and involvement of Artificial Intelligence in modern digital enterprises leads to a considerable reduction of personnel and reorientation of the remaining staff to new responsibilities. However, in many areas like services and support the total elimination of the employed human resources still remains impossible. It is proposed to study the organisational problem of finding the optimal proportion of computer agents and human actors in the mixed collaborative environment.

Methods: Using the technology of semantic and statistical analysis, we developed an original model of computer agents' and human actors' cooperative interaction and an optimization method, which is novel in considering the focus of the executors while calculating the compliance indicators.

Results: The problem was studied by an example of service desk automation. Considering the semantics of the problem domain in the form of ontology introduces the logic for better distribution and automation of tasks.

Conclusion: In a modern digital enterprise there exists and can be estimated a rational balance between the computer agents and human actors, which becomes a significant indicator of its performance. In general, human actors are preferable for processing unpredictable events in real time, while agents are better at the modelling and simulation.

Keywords: Service organisations automation, Artificial intelligence, Human resources, Decision-making support.

\section{Introduction}

Current trends in the automation of modern organisational management require the widespread introduction of artificial intelligence. According to the strategy of total digitalisation, human resources should be replaced by robots capable of performing business processes with higher efficiency and lower costs. In this context, the robots are not only machines but also computer agents with autonomous behaviour that interact in the virtual world and provide self-organisation. Intelligent solutions of this kind stimulate high expectations.

At the same time, their implementation in practice remains challenging. In most business cases it is impossible to completely replace humans by programmes. Sometimes it is hard to formalise all the options of the business process and maintain possible changes; more often, the personnel remain, as they can provide greater adaptability. Therefore, in most real applications both humans and algorithms are involved.

Human and robotic computer-simulated executors need to interact and cooperate in real time under the continuous pressure of incoming data and on-going events, and require sophisticated coordination. People require additional training for acting in vastly automated spaces; algorithms need extra configuration to consider the possible influence of the human factor. In early applications, e.g. production line automation, attempts were made to bound and minimise interaction by physical borders. In modern

Received: 7th July 2020; revised: 5th March 2021; accepted: 26th March 2021 
organisations this is impracticable.

Thereby a new problem appeared of looking for the best balance of artificial and human intelligence, considering the specifics of certain business cases. It seems reasonable to completely replace the human executors in production and provide their maximum utilisation in services, but it is not so simple. Hence, when larger processes involve automation, the remaining personnel start looking for new functions and change their professional skillset, adapting it to the changing world. This process can either enhance the business or damage it. In this paper the problem is studied and solved for a common business case of service desk automation, which has often raised the question: "What is the best proportion of human and robot operators in an organisation?".

This paper originally brings up the question of the necessity and sufficiency of the application of artificial intelligence to practice. The most relevant papers in this area are devoted to the problems of efficient substitution of human resources with robots and improving the computerhuman interaction. The authors propose for consideration an idea of the reasonable involvement of artificial intelligence based on the analysis of business processes specifics. Compared to the previous publications, new results of $\mathrm{AI}$ and HR balancing studied by an example of the service desk automation are presented.

\section{State of the art}

Artificial intelligence is currently becoming one of the most promising areas for discussion and research in the modern world of digitalisation (Patel et al., 2000). By implementing these concepts, traditional enterprises are turning into digitally minded organisations along the path of innovative transformation. A digital enterprise is an organisation that uses information technology as a competitive advantage in all areas of its business: manufacturing, business processes, marketing, and customer interaction. The product itself, offered by such an enterprise to the market, also becomes digital.

Recent developments in the field of artificial intelligence (AI) and augmented reality provide great opportunities in various areas of modern economics and business (One Internet, 2016). The most significant results are being achieved in the field of data visualisation and decision-making support, aimed at developing existing applications with new capabilities for data collection, processing and management. Cognitive computing (Kelly, 2015), the foundation of artificial intelligence, implies the simulation of human brain activity, which allows the machines to process information, learn about the world and analyse events like people do, perhaps even more productively.

New trends in project management (Grzeszczyk, 2018) consider the influence of intelligent information systems, $\mathrm{AI}$ in decision-making support and new information and communication technologies. Mixed intelligence systems are applied for project evaluation, taking into account the current state of knowledge in the field of project management. The possible ways of considering the opportunities of artificial intelligence for pragmatic applications are presented in (Bentley et al., 2018).

Existing models of intelligent technologies implementation in deep cooperation with human employees introduce the concept of the computer agent - an avatar with a pre-programmed profile, actions and communication (Rosen, 2018). In the context of this paper, the term software agent can also be used as a synonym. Computer agents are involved in collaborative problem solving by sharing knowledge and understanding, organising the group work and monitoring the progress, taking actions to solve the problem, and providing constructive feedback to group members.

The introduction of AI capabilities in business leads to a limitation in the same type of operations that are amenable to simple algorithms. This results in a reduction of the number of employees engaged in non-creative and formalised work. Despite the success of such solutions in corporate applications, the problem of the interaction of people and robots in the common information space of an enterprise is still challenging. The interaction of AI and $\mathrm{HR}$ intelligence is identified as mixed intelligence, and the environment in which they interact is combined. The results of a survey by (Grace et al., 2018) predict that AI will outperform humans in many activities that require both technical skills and creativity. A solution to bridge the gap between AI and human-robot interaction is proposed in (Khandelwal et al., 2017). The related ethical problems are overviewed in (Hagendorff, 2020).

The existing approaches to the application of intelligent technologies to improve the staffing of modern organisations typically suggest applying $\mathrm{AI}$ in the area of $\mathrm{HR}$ management. Certainly, introducing intelligent systems for decision-making support in this area can significantly improve the efficiency and quality of projects staffing and management, recruitment and people development (Ivaschenko et al., 2019; Simonova et al., 2016).

For example, the possible applications of Big Data technologies in enterprise HR management are widely discussed in recent literature (Zang et al., 2015; Barman et al., 2015). The challenge is in the use of multiple data sources to improve practices in training, recruitment, performance analysis and motivation. Big Data in HR sets out to evaluate and improve practices including talent acquisition, development, retention, and overall organisational performance.

An interesting approach to the application of the AI concept in human communities is introduced in (Letouze et al., 2018). It is proposed to design future human sys- 
tems based on the principles of interaction and Big Data technologies.

The strengths and weaknesses of human and machine collaboration are reviewed in (Wilson et al., 2018). This paper is close to the topic studied here. In particular, it states that there is no reason to fear that robots will replace all human employees. This research involved 1500 firms in a range of industries and shows that the biggest performance improvements come when humans and smart machines work together, enhancing each other's strengths. When people and AI agents cooperate, the business processes need to be redesigned. As a result, in addition to the implementation of innovative AI technologies, provision should always be made for the development of employees in using the computer-human interfaces and changing their mindset.

This new sphere is called a collaborative intelligence (Kragic et al., 2018; Baratta 2015). Despite the recommendation to build a cooperative IT solution based on the organisation of efficient interaction of robots and humans, no technical methodology is proposed on how to calculate the optimal rate and transfer it to the design of the business process.

Collaborative robots are deeply studied in Industry 4.0 (Djuric et al., 2016; Teixeira et al., 2018). The active application of automation and robotics requires a realistic sense of the best time and place for their use. In the framework of this theory, collaborative robots specifically designed for direct interaction with humans are introduced; a collaborative workspace where robots and humans can perform tasks simultaneously and safely; and collaborative operations in which purpose-designed robots can work safely together with humans. Yet the problems being solved have still always been limited to providing comfortable physical interaction, leaving the challenges of functional co-working unaddressed.

The rapid increase in the share of artificial intelligence in human-computer interaction complicates the search for a solution to the optimal interaction of AI with the employees. A managerial decision should solve two problems: what is the best ratio of AI and people in a mixed interaction, and what are the optimum areas of application of these solutions, taking into account the human factor. The solution of the AI and HR proportion and involvement in the business processes of a digital company needs to be built on the principles of management by conditions (Ivaschenko et al., 2015, 2019, 2020).

As a result, the user is put inside the "loop" of computer-human interaction (Holzinger, 2014, 2016), which requires the user interfaces context and focus to be seen as dependent. The system should interlink all related data sets (e.g., images, text, measured values, scans) and offer visual scenes. It is proposed to involve the decision maker in the process of data processing and visualisation by means of continuously interacting with the system, which helps to optimise the learning behaviour of both humans and algorithms.

The introduction of AI requires additional efforts to provide modified and improved business processes (Simek et al., 2019; Halaska et al., 2018). An orientation to the specifics of the executors is provided by the subject-oriented approach for business processes management (S-BPM), which conceives a process as a collaboration of multiple subjects organised via structured communication (Fleischmann et al., 2013, 2015). These models enable the synchronisation of computer agents and human actors. But they still remain oriented to primarily human decision-making, which becomes insufficient in the case of the predominance of robots over the human operators.

In addition, the principle of decentralised decisions means the ability of a cyber-physical system to make decisions on its own and to perform tasks as autonomously as possible. The simulation and modelling of models of multi-agent technology (Wooldridge, 2002; Gorodetskii, 2012) allow the implementation of such autonomous behaviour by software and thus provide the effect of self-organisation.

To coordinate computer agents and human actors on a semantic level, the mechanism of knowledge description in the form of ontologies can be used (Pouchard et al., 2000; De Nicola et al., 2009). Ontology represents the semantic network, combining concepts, attributes, relations and rules that describe the situation from a predefined point of view. The functioning of the organisation staff is highly influenced by the human factor, that is to say that people perceive different situations differently, although, for a certain problem domain, the employees tend to agree on a similar perception and understanding. Due to this fact, problem domain ontologies are treated as impersonal and objective. The ontologies of computer agents can be formally predefined and used to specify the definite and explicit logic of their behaviour.

One of the potential problem domains that require optimisation of the proportion of intelligent technologies applied is service desk automation. Its process involves online collaboration and the provision of IT services to customers. Ensuring the constant high quality of IT services and customer or user satisfaction is implemented based on the approach (Axelos, 2019; England, 2008) described by the IT Infrastructure Library (ITIL). It focuses on the achievement of goals, the analysis of key performance indicators, as well as the resources spent on achieving goals. ITIL includes a set of documents used for the practical implementation of IT Service Management (ITSM) approaches, which will include the basic processes that support and provide IT services. Service management is implemented by IT providers by using the optimal combination of people, processes and information technology.

In the structure of ITIL and ITSM processes, the service desk plays an important role, carrying out accounting, 
registration of tasks, solution and tracking of issues. Next, we will consider the flow of tasks received from users and their processing in the service desk system. Tasks arrive on the service desk at random times and form a task queue. Then, the tasks go to a group of specialists who take them out of the line independently, so we cannot uniquely identify a specific executor. All personnel from the working group are interchangeable.

\section{The formal model}

The following formal model is based on an ontological approach that allows the definition of the semantics of any object $x_{n}$ by a knowledge descriptor:

$$
\omega\left(x_{n}, t_{n}\right)=\left\{\left\{\tau_{n, l}, w_{n, l}\right\},\left\{p\left(x_{n^{\prime}}\right)\right\}, t_{n}\right\},
$$

where $\tau_{n, l}$ is a tag (keyword), $w_{n, l}$ its weight, $p\left(x_{n^{\prime}}\right)$ defines the relation to another descriptor $x_{n^{\prime}}$, $t_{n}$ - the time of the descriptor's applicability.

Concepts relate to the objects, weighted tags correspond to the attributes, and their dependencies are described by relationships. The basic rule required in this context determines the criterion of proximity. Objects $x_{n}$ and $x_{n^{\prime}}$ are ontologically close when

$$
\begin{aligned}
& P\left(\omega\left(x_{n}, t_{n}\right), \omega\left(x_{n^{\prime}}, t_{n^{\prime}}\right)\right)=\sum_{n, l}\left|w_{n, l}-\sum_{n^{\prime}, l^{\prime}} w_{n^{\prime}, l^{\prime}} \cdot \delta\left(\tau_{n, l}=\tau_{n^{\prime}, l^{\prime}}\right)\right|+ \\
& +\sum_{n^{\prime}, l^{\prime}}\left|w_{n^{\prime}, l^{\prime}}-\sum_{n, l} w_{n, l} \cdot \delta\left(\tau_{n, l}=\tau_{n^{\prime}, l^{\prime}}\right)\right| \leq \Delta W,
\end{aligned}
$$

where $\Delta W$ is an allowable level of semantic deviation,

$$
\delta(x)=\left\{\begin{array}{l}
1, x \geq 0 \\
0, x<0
\end{array}\right.
$$

Let us study the combined environment of a digital enterprise that contains both human actors $a_{i}, i=1 . N_{a}$ and computer agents $b_{j}, j=1 . N_{b} . N_{a}$ and $N_{b}$ represent the number of actors and agents respectively. Both actors and agents have corresponding knowledge descriptors: $\omega\left(a_{i}\right)$ and $\omega\left(b_{j}\right)$.

A typical service desk implements standardised business processes according to which actors and agents need to perform certain tasks $d_{k}$ or actions at specified moments. Therefore the work process can be formulated by a scenario:

$\varepsilon_{r}=\left\{s_{k}\left(d_{k}, t_{k}, \Delta t_{k}, \omega\left(d_{k}, t_{k}\right), t_{k}^{0}\right)\right\}$,

where $\omega\left(d_{k}, t_{k}\right)$-is the requirement for the executor, $t_{k}$ - time for the task to start,

$t_{k}^{0}$ - task appearance time, $t_{k}^{0} \leq t_{k}$,
$\Delta t_{k}$ - its normative duration.

For similar operations, specified template scenarios for the generation of new states for every new order can be used.

To start a task an appropriate executor should be available and be assigned to it. An assignment event for the actor $a_{i}$ is specified as

$$
q_{k, i}^{\prime}=q_{k, i}^{\prime}\left(d_{k}, a_{i}, t_{k, i}^{\prime}, \Delta t_{k, i}, \omega\left(a_{i}^{\prime}, t_{i}^{a}\right)\right),
$$

where the sequence of descriptors $\omega\left(a_{i}, t_{i}^{a}\right)$ describes how the actor's focus changes with time.

An assignment event for the agent $b_{j}$ is specified correspondingly:

$q_{k, j}^{\prime \prime}=q_{k, j}^{\prime \prime}\left(d_{k}, b_{j}, t_{k, j}^{\prime \prime}, \Delta t_{k, j}, \omega\left(b_{j}, t_{j}^{b}\right)\right)$,

The process of task flow distribution between the agents and actors in real time is characterised by the following average indicators:

- $\quad$ processing time;

- downtime or waiting time (idle time when waiting for assignment and start);

- the number of failures.

In problem domains like service desk automation the process of tasks execution involves multiple negotiations with the consumer and is performed in real time. Therefore the difference between the processing time by computer agents or human actors does not differ. When processing the task flow, the system goal is to minimise the number of execution failures and the task processing timeout.

Using the introduced indicators, we reduce the process of determining the optimal percentage ratio of agents and actors to solving the optimisation problem of discrete programming that includes the following objective functions.

Minimum waiting time (downtime):

$$
T=\sum_{k} \sum_{i} \sum_{j} s_{k} \cdot\left(q_{k, i}^{\prime} \cdot\left(t_{k, i}^{\prime}-t_{k}^{0}\right)+q_{k, j}^{\prime \prime} \cdot\left(t_{k, j}^{\prime \prime}-t_{k}^{0}\right)\right) \rightarrow \min .
$$

Minimum number of failures:

$$
F=\sum_{k} \sum_{i} \sum_{j} s_{k} \cdot\left(1-q_{k, i}^{\prime}\right) \cdot\left(1-q_{k, j}^{\prime \prime}\right) \rightarrow 0 .
$$

The proposed model has the following main assumptions and limitations.

1. The application of intelligent technologies in the modern organisation is concerned with the reduction of personnel and reorientation of the remaining staff to new responsibilities. Therefore, during the time of AI implementation, agents and actors are considered interchangeable.

2. The quality of tasks being performed by human actors is not compared to the quality of computer agents. If the task is carried out by any executor on time and with acceptable quality it is treated as successfully done. Otherwise it is treated as "rejected". 
3. The difference between the normative duration of task execution by a human employee or robot, as well as the difference in cost, is not taken into account here. These parameters are influenced by the number of frequently repeated typical tasks. Computer agents are preferable for typical tasks, and human executors react better to unique occasional events. Therefore the problem of costs and time optimisation remains outside the scope of this study.

4. We consider that the efficiency characteristics of the computer agents and human actors are constant and do not change over time, and the number of tasks that need to be processed also remains unchanged.

\section{Method}

The solution of the problem $(6,7)$ is formulated as a set of assignment events $\left\{q_{k, i}^{\prime}\right\} \cup\left\{q_{k, j}^{\prime \prime}\right\}$. In order to process the incoming event flow of tasks $\left\{s_{k}\right\}$, the system should provide available resources of a certain type (agents or actors) at the required moments of time. The main problem is that we can neither attract additional employees when needed nor keep additional staff in reserve.

Therefore the proposed method contains three main stages: agents/actors ratio optimisation, compliance analysis and assignment. The generalised schema of the method is presented in Fig. 1. This method can be implemented using either standard software for simulation and analysis or a specifically designed software solution.

The first stage is to determine the quantitative ratio of agents and actors for efficient processing of the flow of incoming tasks. In the case of low knowledge about the real amount and types of tasks, event flows are simulated.

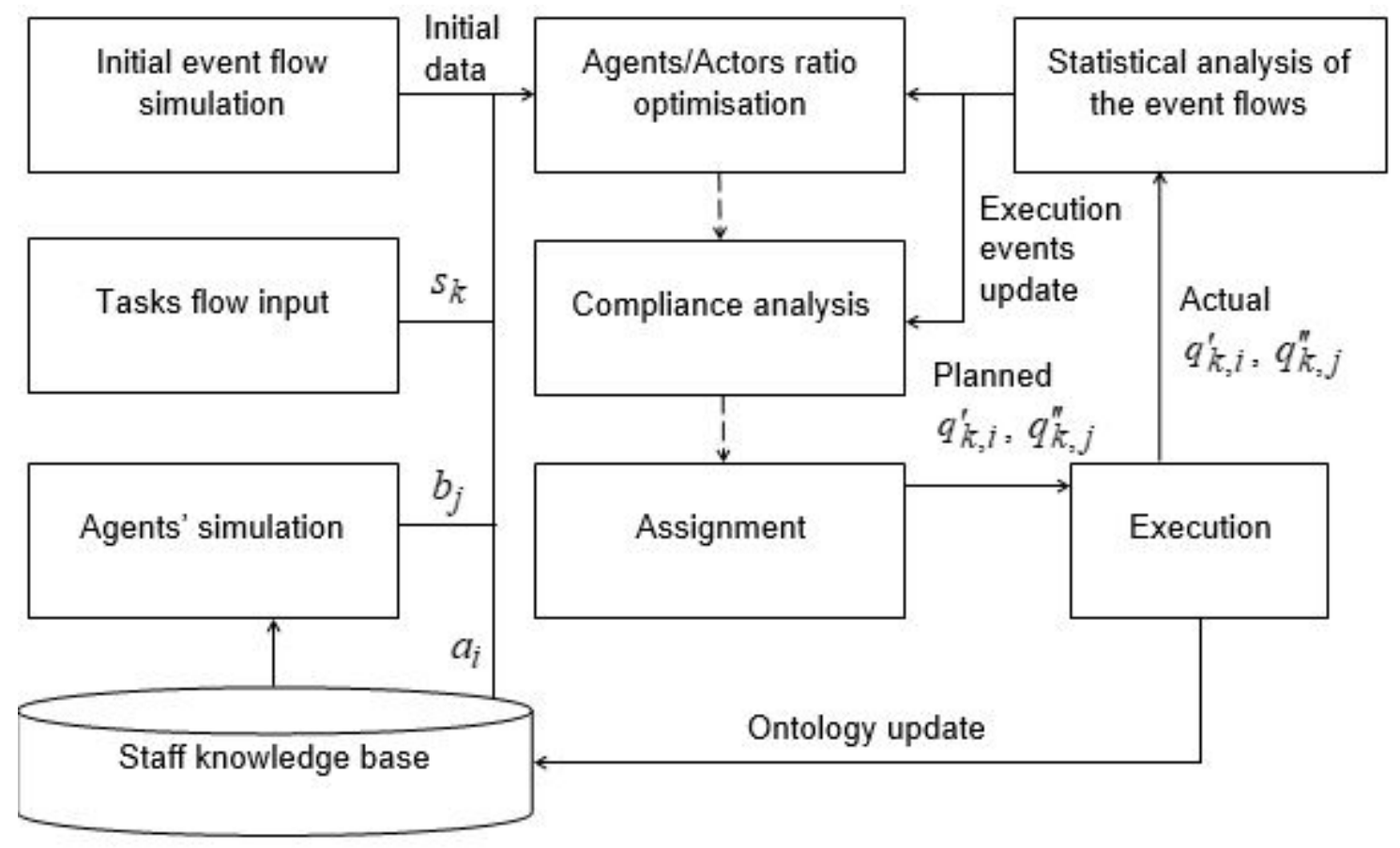

Figure 1: The method of optimisation of the rational proportion of intelligent technologies application

The first stage is to determine the quantitative ratio of agents and actors for efficient processing of the flow of incoming tasks. In the case of low knowledge about the real amount and types of tasks, event flows are simulated.

As a starting point, we consider an option with the number of actors $N_{a}=1$, and the proportion

$N_{b} /\left(N_{a}+N_{b}\right) \quad=100 \%$, which corresponds to the complete execution of tasks by people, without the use of automated robotic systems.

Next, we consider the option in which the number of agents is $N_{b}=1$. It corresponds to fully automatic processing of incoming tasks. With this distribution, the waiting time for tasks in the queue is reduced, but the number of failures has the potential to increase, since the agents are able to perform poorly formalised tasks.

To determine the point at which both objective func- 
tions are minimal, we use the gradient descent method with step splitting. The geometric interpretation of the method is that at each step we move along the anti-gradient vector, reduced by $\gamma$ times, determining the direction of optimisation. Based on this data, a balance graph is constructed, which displays the intersection point of two functions, which corresponds to the optimal percentage ratio of agents and actors.

Compliance analysis is performed to improve the quality of the matching of the incoming tasks to the most appropriate executors. In order to provide on-time processing of incoming tasks, agents and actors need to be assigned correspondingly. Considering their autonomous behaviour and self-organisation, this should be done indirectly by attracting their attention at required moments. The result is described by the following compliance indicator:

$R_{a}=\sum_{k} \sum_{i}\left(s_{k} \cdot q_{k, i}^{\prime} \cdot P\left(\omega\left(d_{k}, t_{k}\right), \omega\left(a_{i}, t_{i}^{a}\right)\right)\right.$.

$\left.\cdot \delta\left(t_{k, i}^{\prime} \leq t_{k}<t_{k, i}^{\prime}+\xi\right) \cdot \delta\left(t_{i}^{a} \leq t_{k, i}^{\prime}<t_{i+1}^{a}\right)\right) \rightarrow \max$,

where $t_{i}^{a}$ - focus time (time of actor changing his/her interest represented by semantic descriptor);

$t_{k, i}^{\prime}$ - assignment time, $t_{k}^{0} \leq t_{k, i}^{\prime} \leq t_{k}$.

Compliance indicator (5) allows the main correlations between the event flows of tasks and assignment to agents or actors to be determined. Compared to the high dynamics of $\omega\left(a_{i}, t_{i}^{a}\right)$ being forced by changes of the actors' interest, the focus of each agent $\omega\left(b_{j}, t_{j}^{b}\right)$ does not change with time.

The compliance indicator for agents represents their impact:

$$
\begin{aligned}
& R_{b}=\sum_{k} \sum_{j}\left(s_{k} \cdot q_{k, j}^{\prime \prime} \cdot P\left(\omega\left(d_{k}, t_{k}\right), \omega\left(b_{j}, t_{j}^{b}\right)\right) .\right. \\
& \left.\cdot \delta\left(t_{k, j}^{\prime \prime} \leq t_{k}<t_{k, j}^{\prime \prime}+\xi\right) \cdot \delta\left(t_{j}^{b} \leq t_{k, j}^{\prime \prime}<t_{j+1}^{b}\right)\right) \rightarrow \max .
\end{aligned}
$$

Considering the limited number of tasks, statements (8) and (9) are in contradiction. To maximise the number of agents, the statement (8) should be targeted first, then the number of skipped tasks is reduced and assigned to corresponding human actors by attracting their interest.

Such an approach provides an efficient proportion of computer agents and human actors in the mixed intelligence. In general, human actors turn out to be preferable for processing unpredictable events in real time, while AI agents are better at simulating multiple versions of possible situations to predict, analyse, compare and optimise.

Assignment is the last stage of the method that generates the planned flows of $\left\{q_{k, i}^{\prime}\right\} \cup\left\{q_{k, j}^{\prime \prime}\right\}$. The tasks are not assigned declaratively, but proactively taken out from the common queue by agents and actors according to their preferences. Actors pick out the tasks for execution themselves, while the agents are assigned automatically.

Based on the execution history, the knowledge base is updated in automatic mode. The staff knowledge base is

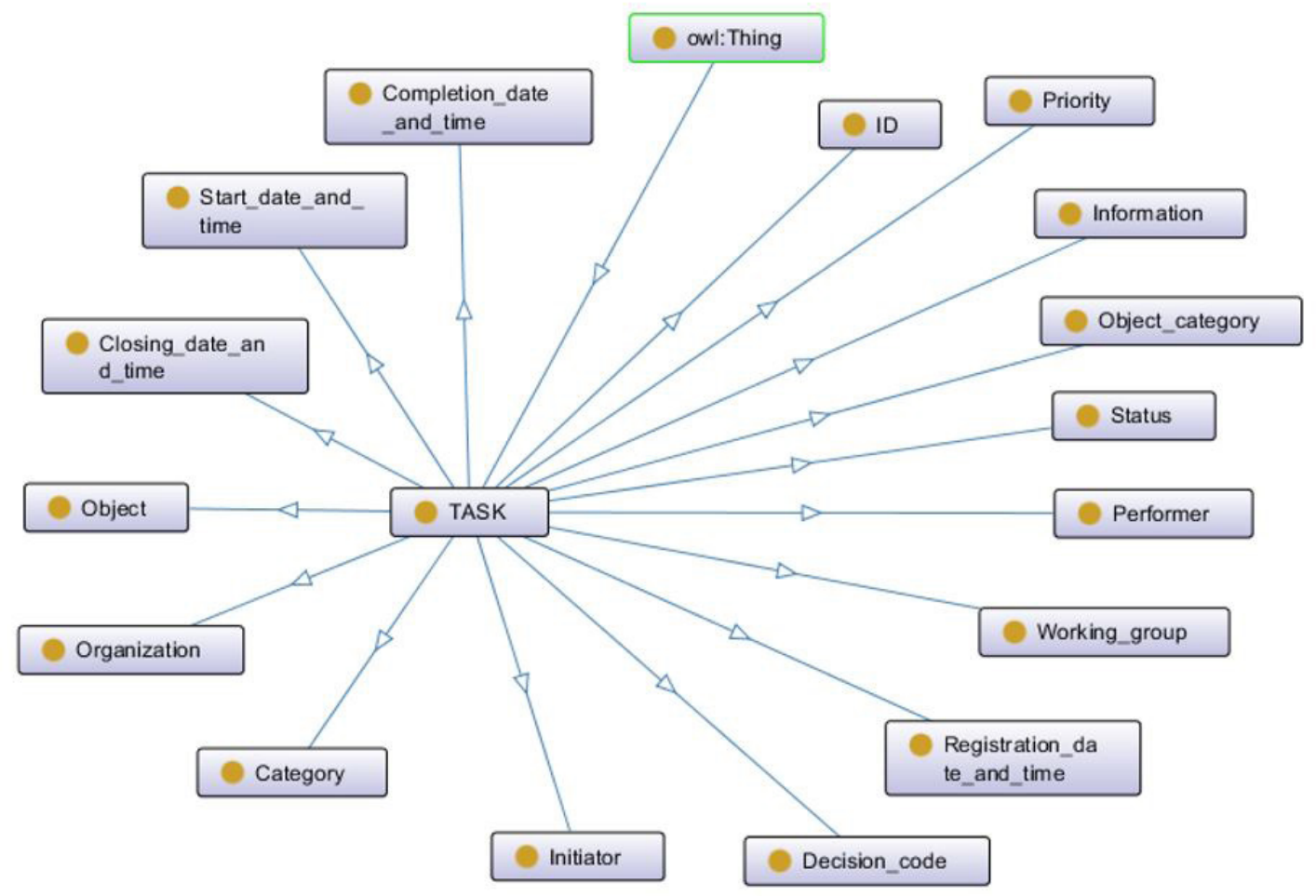

Figure 2: Task ontoogy 


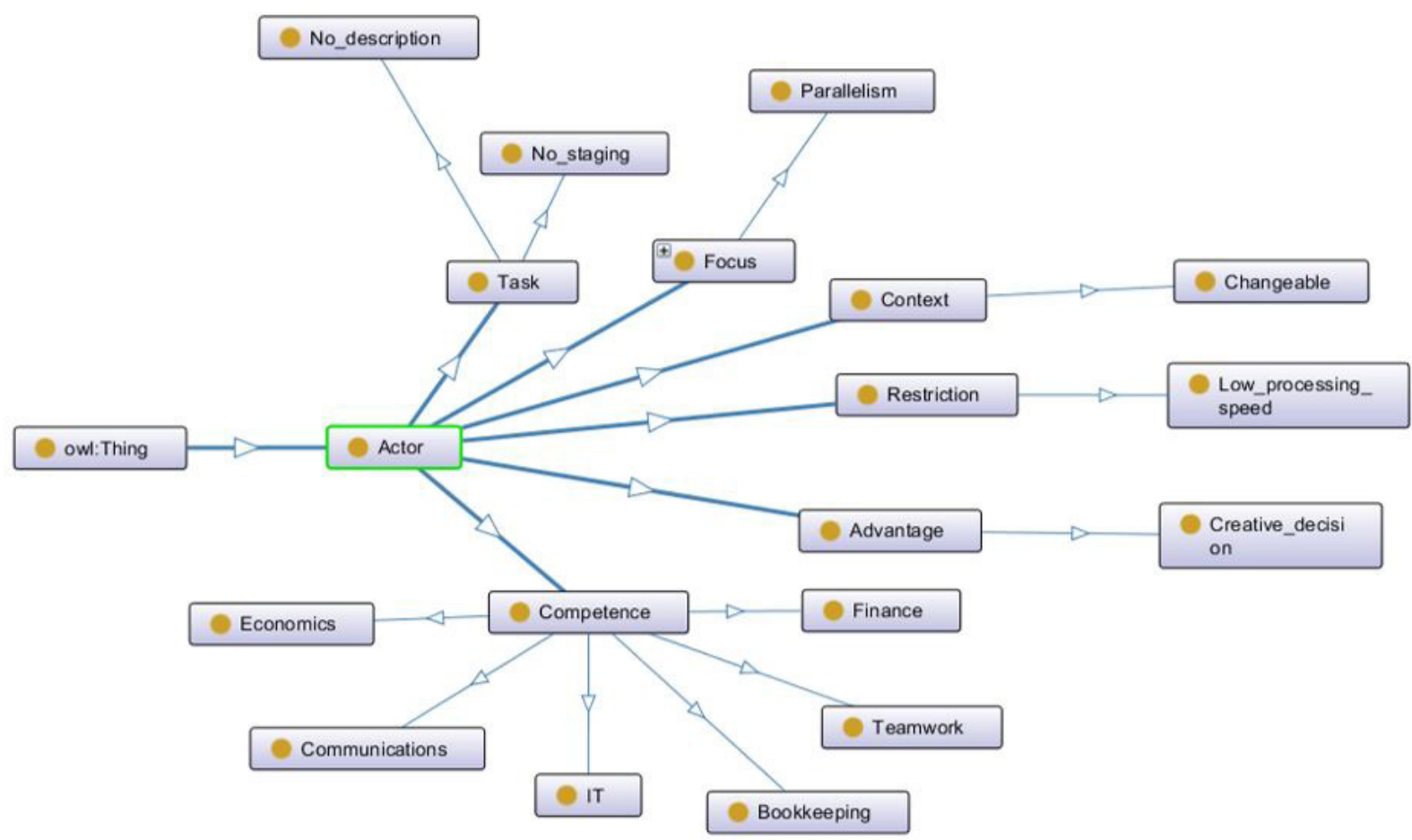

Figure 3: Actor ontology

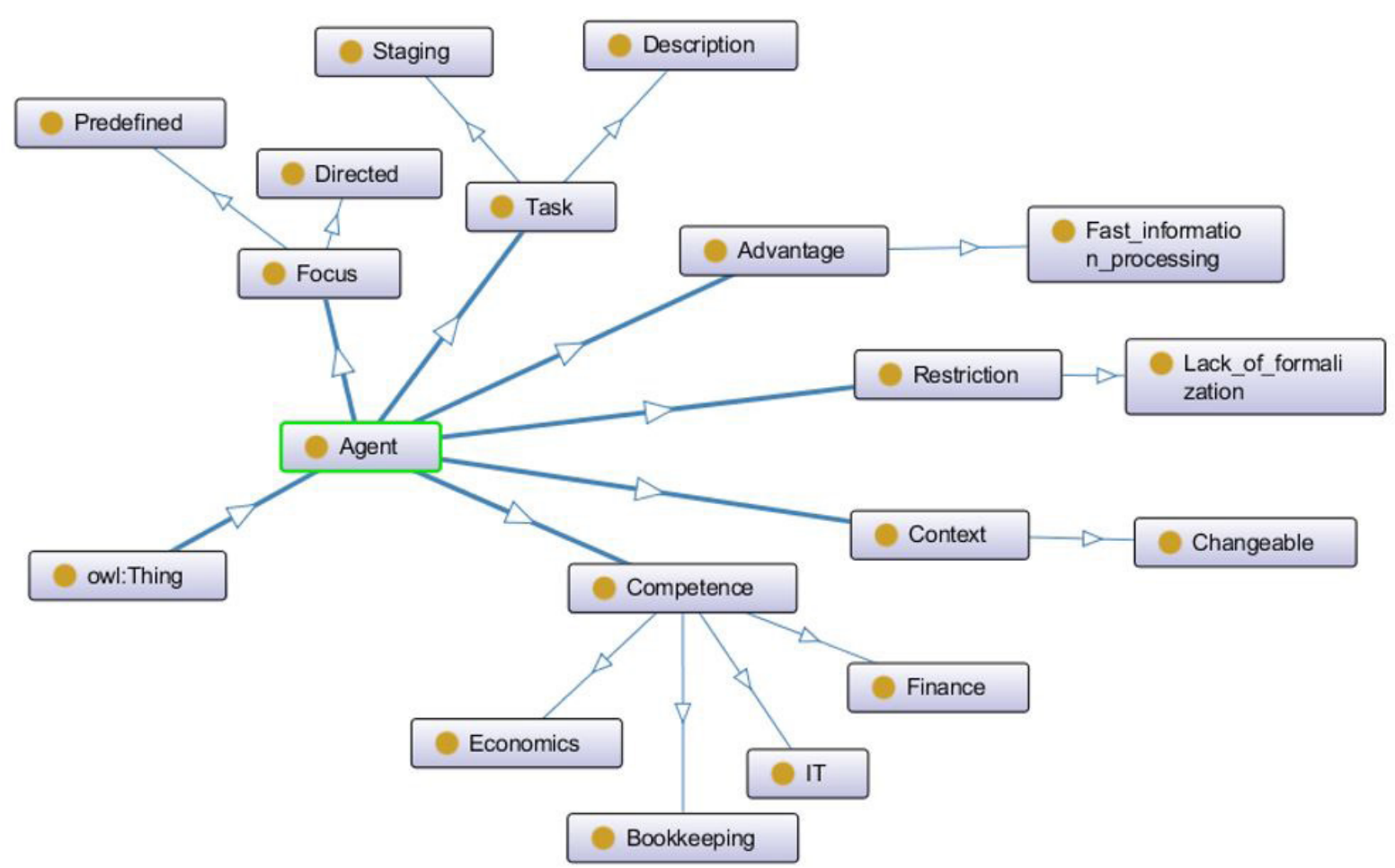

Figure 4: Agent ontology 
used to simulate the agents of new types and data processing at the optimisation stage.

Considering the features of agents and actors, as well as the difference in the criteria for interaction and task processing, the staff knowledge base is combined from the ontologies of the task (see Fig. 2), the actor (see Fig. 3) and the agent (see Fig. 4). They present the main concepts in the form of a semantic model of RDF data and are visualised by OntoGraf - a conceptual map, which can be equated to a semantic network, since it has a network structure, the ability to specify the type of connection, uses words at the vertices, and has multiple connections between the concepts. The model visualisation is presented using Protégé: a local, freely distributed Java program designed to build (create, edit and view) ontologies of the application area.

The developed ontologies are necessary to introduce the hierarchical structure of the criteria for fulfilling tasks, which makes it possible to determine the relationships, differences and similarities between the ontologies of tasks and their executors.

\section{Service desk case studies}

The problem of AI and HR balancing was studied by an example of service desk automation. We have taken a dataset of 648 real calls that require service tasks generation and processing during a fixed period of time. The data was taken from the real service desk centre of an IT company and contains support requests. The call flow was divided into three types: Information request, Providing access, and Closing access.

According to the model and problem statement introduced above, the system goal is to minimise the number of execution failures and the task processing timeout. For the initial calculations, the averaged parameters of the speed of processing calls, the number and time of downtime for agents and actors were determined. These parameters were analysed using the statistical analysis software package STATISTICA by StatSoft. More details about the analysis are presented in the appendix.

According to the method introduced, for $N_{a}=1$ the failure rate was zero, but the downtime increased by 1.9

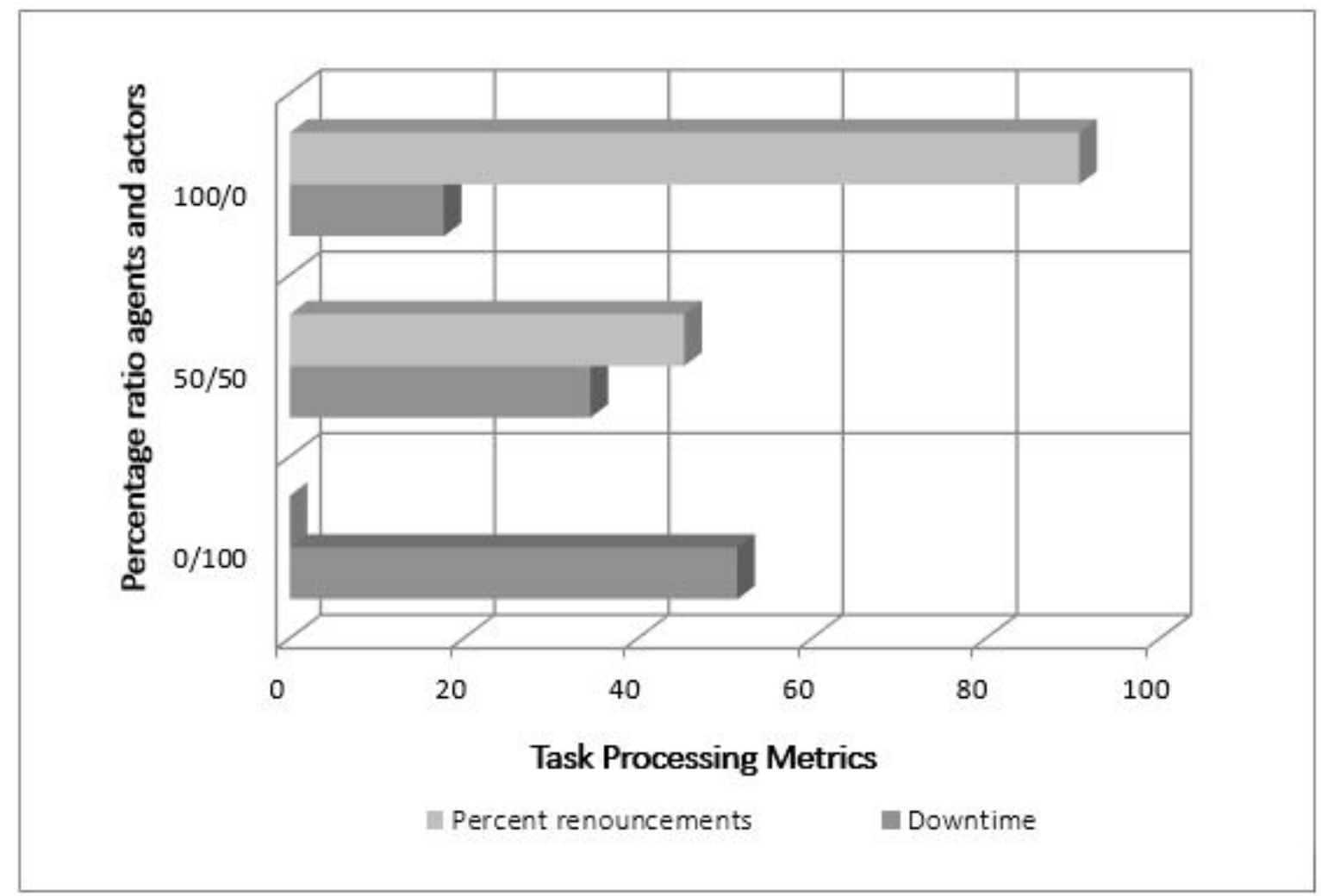

Figure 5: Dependency of tasks processing metrics for different agents/actors ratio 
times compared to the initial values obtained. For $N_{b}=0$ the waiting time for tasks in the queue was reduced by 1.4 times, but the number of failures reached 90 tasks due to renouncements and showed a tendency to increase, since the agents were able to perform poorly formalised tasks. An option was also considered in which the number of agents and actors was equally divided. Based on the calculations made, a graph was built (see Fig. 5). The graph shows how the performance indicator changes depending on the percentage of agents and actors for the objective functions introduced.

Based on the data obtained by the gradient descent method for two objective functions, a balance graph was constructed (see Fig. 6), which displays the intersection point of two functions, which corresponds to the optimal percentage ratio of agents and actors.

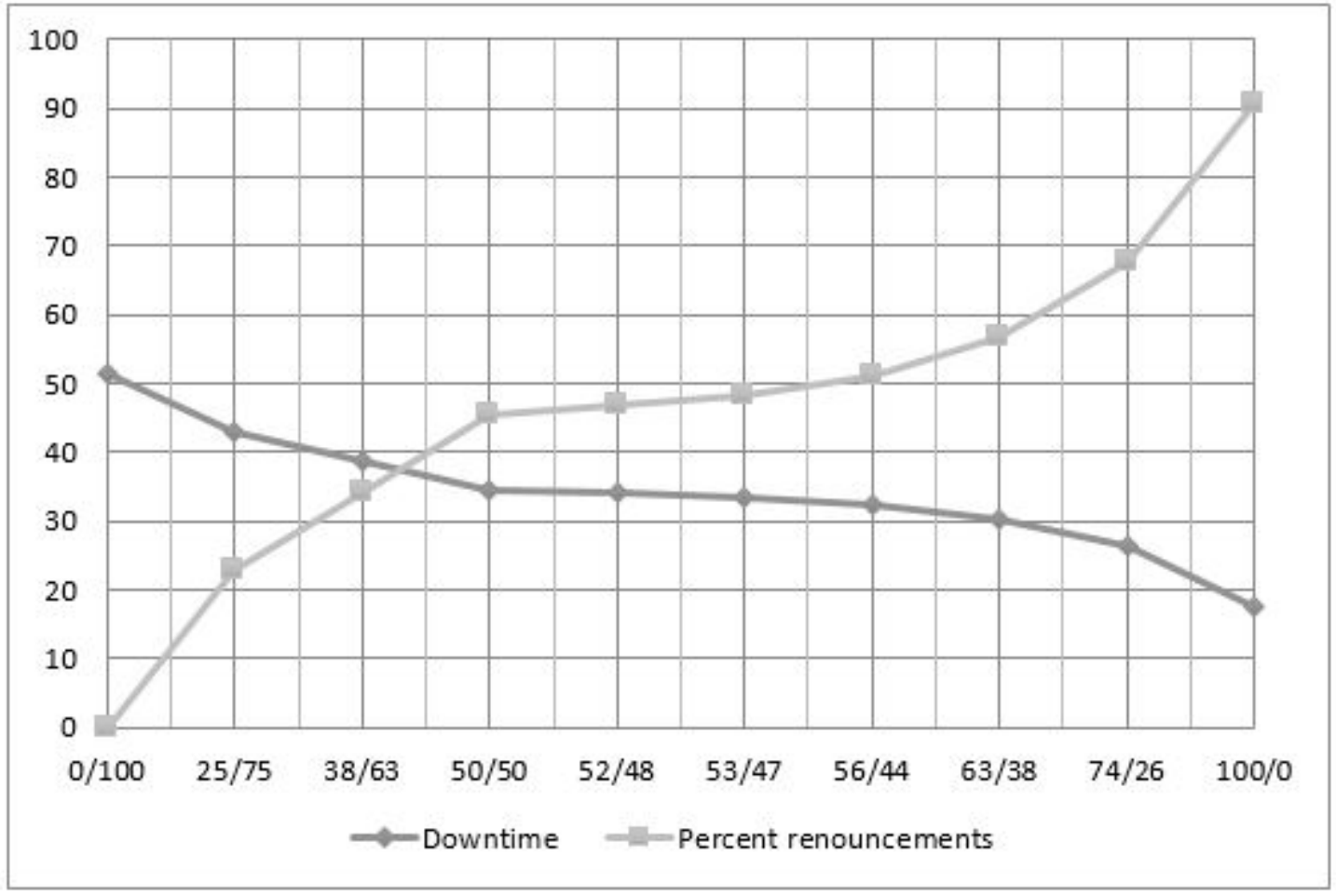

Figure 6: Dependency of failures on waiting time

\section{Conclusion}

Analysis and testing of AI and HR balancing in theory and practice gives a new idea for organisational management to look for the optimal percentage ratio of computer agents and human actors. Herewith, while solving this problem, the main objective should be changed from the total or maximum possible replacement of executors by software and robots to a rational combination of artificial and human executors, targeting their maximum cooperation.

Therefore in a modern digital enterprise there exists and can be estimated a rational proportion of computer agents and human actors, which becomes a significant indicator of their performance. This parameter varies with time depending on the business requirements. In general, human actors are preferable for processing unpredictable events in real time, while agents are better at the modelling and simulation of multiple possible situations for forecasting, analysis, comparison, and optimisation.

The results of the performed analysis of service desk automation applying a rational proportion of intelligent technologies helped to formulate the main differences and features of the subjects of mixed intelligence, presented in Table 1. This conclusion may be of interest to the developers of modern AI solutions based on multi-agent technologies and network organisational structures.

The actors have the prospect of a deeper and more creative execution of tasks. At the same time, in mixed teams, dealing with a rapid change in context, the advantage will be on the side of the agents. Considering the theory of or- 
ganisational management and the influence of the human factor, the approaches to stimulating agents and actors should be different. The actors need to understand the benefits of their involvement and the impossibility of their total replacement by agents. The agents should provide stable and reliable services and be able to cooperate with the actors to develop new business opportunities. To reduce the amount of waiting time specifically for the actors, it is necessary to attract their attention to urgent tasks in the necessary steps of the business processes.
As presented in this paper, the complete replacement of personnel leads to a lack of adaptability, while the introduction of additional artificial intelligence gives new opportunities and advantages. Besides, the employees of modern companies need to decide nowadays what area of their impact will be the most beneficial and adopt training paths and development strategies accordingly.

Table 1: Features of mixed intelligence subjects

\begin{tabular}{|l|l|l|}
\hline \multicolumn{1}{|c|}{ Criterion } & \multicolumn{1}{|c|}{ Computer agent } & \multicolumn{1}{c|}{ Human actor } \\
\hline Time & Model time & Real time \\
\hline Reality & Able to simulate multiple versions of scene & $\begin{array}{l}\text { Capable of acting in real scene or a few } \\
\text { forecast scenes }\end{array}$ \\
\hline Focus & Rigid and predefined & $\begin{array}{l}\text { Flexible, changing under the influence of } \\
\text { interest }\end{array}$ \\
\hline Role & Reliable and predictable & Highly qualified and motivated \\
\hline Context influence & No & Considerable \\
\hline Problem statement & Formalised & Lacking \\
\hline Limitations & $\begin{array}{l}\text { Unable to solve unique and poorly for- } \\
\text { malised tasks }\end{array}$ & Low productivity \\
\hline Strengths & High performance & High adaptability \\
\hline Switching between tasks & Needs study time & Low study time \\
\hline
\end{tabular}

\section{Literature}

Axelos (2019). ITIL Foundation, ITIL 4th ed. UK: TSO (The Stationery Office), 222.

Baratta, D. (2015). Industrial collaborative robot design. A guideline for future design activity. CEUR Workshop Proceedings, Vol 1473. Artificial Intelligence and Design AIDE 2015. http://ceur-ws.org/Vol-1473, 7

Barman, A., Ahmed, H. (2015). Big Data in human resource management - developing research context. http:// doi.org/10.13140/RG.2.1.3113.6166

Bentley, P.J., Brundage, M., Haggstrom, O., Metzinger, T., Gutenberg, J. (2018). Should we fear artificial intelligence? STOA - Science and Technology Options Assessment, 40. http://dx.doi.org/10.2861/412165

De Nicola, A., Missikoff, M., Navigli, R. (2009). A software engineering approach to Ontology building. Information Systems, 34(2), 258-275. http://dx.doi.or$\mathrm{g} / 10.1016 / \mathrm{j}$.is.2008.07.002

Djuric, A., Urbanic, R.J., Rickli, J. (2016) A framework for collaborative robot (CoBot) integration in advanced manufacturing systems. SAE International Journal of Materials and Manufacturing, 9. http://doi. org/10.4271/2016-01-0337

England, R. (2008). Introduction to real ITSM. CreateSpace Independent Publishing Platform.

Fleischmann, A., Kannengiesser, U., Schmidt, W., Stary, C. (2013). Subject-oriented modeling and execution of multi-agent business processes. Web Intelligence (WI) and Intelligent Agent Technologies (IAT), 2013 IEEE/ WIC/ACM International Joint Conferences, 138-145. https://doi.org/10.1109/WI-IAT.2013.102

Fleischmann, A., Schmidt, W., Stary, C. (2015). S-BPM in the wild. Springer. http://doi.org/10.1007/978-3-31917542-3

Gorodetskii, V.I. (2012). Self-organization and multiagent systems: I. Models of multiagent self-organization. Journal of Computer and Systems Sciences International, 51(2), 256-281. https://doi.org/10.1134/ S106423071201008X

Grace, K., Salvatier, J., Dafoe, A., Zhang, B., Evans, O. (2018). When will AI exceed human performance? Evidence from AI experts, https://arxiv.org/ pdf/1705.08807.pdf, 21

Grzeszczyk, T.A. (2018). Mixed intelligent systems. Developing models for project management and evaluati- 
on. Palgrave Pivot https://doi.org/10.1007/978-3-31991158-8

Hagendorff, T. (2020). The ethics of AI ethics: an evaluation of guidelines. Minds \& Machines, 30, 99-120. https://doi.org/10.1007/s11023-020-09517-8

Halaska, M., Sperka, R. (2018). Is there a need for agent-based modelling and simulation in business process management? Organizacija, 51(4), 255-270. https:// doi.org/10.2478/orga-2018-0019

Holzinger, A. (2014). Extravaganza tutorial on hot ideas for interactive knowledge discovery and data mining in biomedical informatics. Lecture Notes in Artificial Intelligence, 8609, 502-515 https://doi.org/10.1007/9783-319-09891-3_46

Holzinger, A. (2016). Interactive machine learning for health informatics: when do we need the human-in-the-loop? Brain Informatics, 3(2) 119-131. https://doi. org/10.1007/s40708-016-0042-6

Ivaschenko, A., Khorina, A., Sitnikov, P. (2019). Online creativity modeling and analysis based on Big Data of social networks. Advances in Intelligent Systems and Computing, 858, 329-337. https://doi. org/10.1007/978-3-030-01174-1_25

Ivaschenko, A., Korchivoy, S., Spodobaev, M. (2020). Infrastructural models of intermediary service providers in digital economy. Advances in Intelligent Systems and Computing, 1038, 594 - 605. https://doi. org/10.1007/978-3-030-29513-4_44

Ivaschenko, A., Milutkin, M. (2019). HR decision-making support based on natural language processing. Communications in Computer and Information Science, 1083, 152-161. https://doi.org/10.1007/978-3-03029743-5_12

Ivaschenko, A.V., Barabanov, V.F., Podvalny, E.S. (2015). Conditional management technology for multiagent interaction. Automation and Remote Control, 76(6), 1081- 1087. https://doi.org/10.1134/ S0005117915060119

Ivaschenko, A.V., Simonova, M.V., Sitnikov, P.V., Shornikova, O.V. (2019). Big Data analysis for HR management at production enterprises. The European Proceedings of Social \& Behavioural Sciences EpSBS. Vol. LVII - GCPMED 2018. Future Academy. 463-471. https://dx.doi.org/10.15405/epsbs.2019.03.46

Khandelwal, P., Zhang, S., Sinapov, J., Leonetti, M., Thomason, J., Yang, F., Gori, I., Svetlik, M., Khante, P., Lifschitz, V., Aggarwal, J., Mooney, R., Stone, P. (2017). BWIBots: A platform for bridging the gap between AI and human-robot interaction research. The International Journal of Robotics Research, 36, 1-25. https:// dx.doi.org/10.1177/0278364916688949

Kelly III, J. (2015). Computing, cognition and the future of knowing. IBM Research: Cognitive Computing. IBM Corporation.

Kragic, D., Gustafson, J., Karaoguz, H., Jensfelt, P., Krug,
R. (2018). Interactive, collaborative robots: challenges and opportunities. Proceedings of the 27th International Joint Conference on Artificial Intelligence (IJCAI-18), 2018, 18-25 https://doi.org/10.24963/ ijcai.2018/3

Letouze, E., Pentland, A. (2018). Towards a human artificial intelligence for human development. ITU Journal: ICT Discoveries, Special Issue 2

One Internet (2016). Global Commission on Internet Governance. https://www.cigionline.org/initiatives/global-commission-internet-governance

Patel, K., McCarthy, M.P. (2000). Digital transformation: the essentials of e-business leadership. KPMG/McGraw-Hill

Pouchard, L., Ivezic, N., Schlenoff, C. (2000). Ontology engineering for distributed collaboration in manufacturing. Proceedings of the AIS2000 Conference.

Rosen, Y. (2018). Computer agent technologies in collaborative learning and assessment. Encyclopedia of Information Science and Technology (4th edn.). IGI Global, 2402-2410 https://doi.org/10.4018/978-1-5225-22553.ch209

Simek, D., Sperka, R. (2019). How robot/human orchestration can help in an HR department: A case study from a pilot implementation. Organizacija, 52(3), 204-217. https://doi.org/10.2478/orga-2019-0013

Simonova, M., Ilyukhina, L., Bogatyreva, I., Vagin, S., Nikolaeva, K. (2016). Conceptual approaches to forecast recruitment needs at the regional level. International Review of Management and Marketing, 6(5), 265-273.

Teixeira, J.V.S., Reis, A.M., Mendes, F.B., Vergara, L.G.L. (2019). Collaborative Robots. Occupational and Environmental Safety and Health. Studies in Systems, Decision and Control, 202. Springer, Cham, 791-796. https://doi.org/10.1007/978-3-030-14730-3_83

Wilson, H.J., Daugherty, P.R. (2018). Collaborative intelligence: humans and AI are joining forces. Harvard Business Review, July-August 2018, 11.

Wooldridge, M. (2002). An introduction to multi-agent systems. John Wiley and Sons, Chichester.

Zang, S., Ye, M. (2015). Human resource management in the era of Big Data. Journal of Human Resource and Sustainability Studies, 3, 41-45. https://doi. org/10.4236/jhrss.2015.31006

Anton Ivaschenko, professor, PhD (2004) in mathematical modeling, DSc (2012) in management in social and economic systems is a Head of the Computer Science Department of Samara State Technical University. His areas of research include modeling of complex systems in digital economy and social media, intelligent and multi-agent systems. 
Alfiya R. Diyazitdinova, PhD (2004) in management in social and economic systems, associate professor at the Applied Informatics Department of Povolzhskiy State University of Telecommunications and Informatics. Her areas of research include IT design and management and automated decision-making support.
Tatiyana Nikiforova is a PhD student at Samara State Technical University, earned her Engineer of Information Systems and Technologies degree in 2015. Her research interests include modeling, business analysis, digital economy and data analysis. 


\section{Appendix}

This appendix contains additional information describing the data studied as an example of service desk automation. The dataset contains 648 real calls that require the generation and processing of service tasks during a fixed period of time.

From the total number of requests, the ratio processed by agents and actors is presented in Fig. 7. 74\% of 648 calls were performed by agents, the remaining $26 \%$ by actors. Fig. 8 describes the distribution of call categories.

Below are presented the main metrics for processing the requests, depending on the executor. The waiting time for tasks execution is presented in the "Boxplot by Group" chart in Fig. 9. The graph shows that the actors (group 1) have a higher idle time than the agents (group 2). The standard deviation is in the range from half an hour to 3 hours. This is due to the fact that the queue of tasks is analysed unevenly by the actors, confirming that the focus of the actor is discrete and constantly changing. For group 2, the standard deviation does not exceed a couple of minutes, which suggests that the tasks for the agents are distributed at a speed that does not allow queuing.

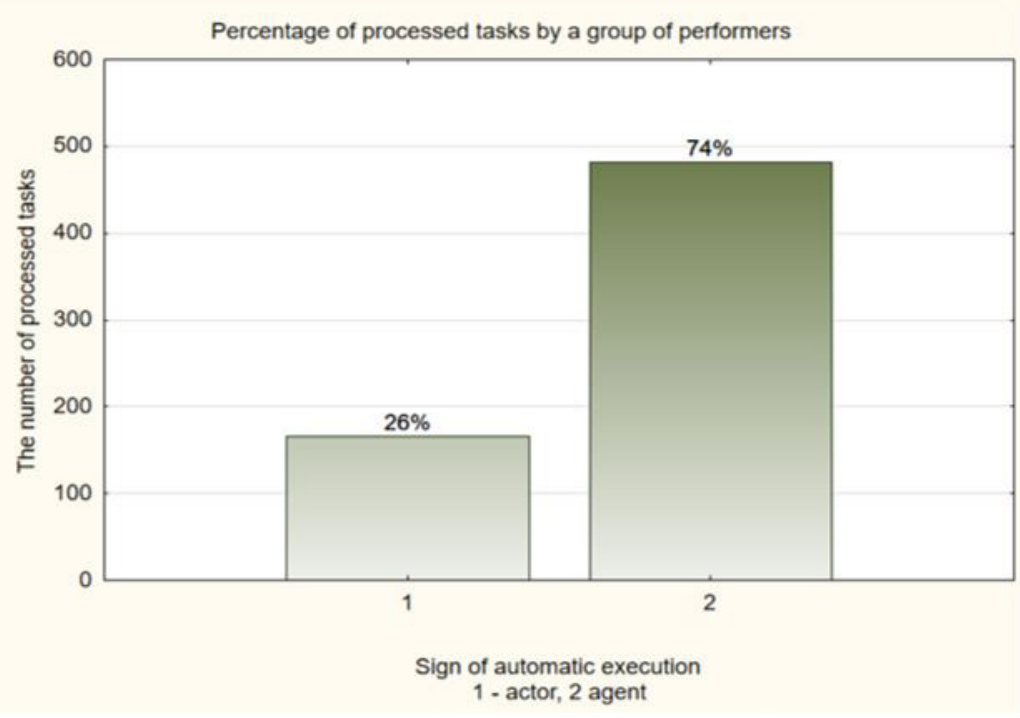

Figure 7: Tasks processed by actors and agents

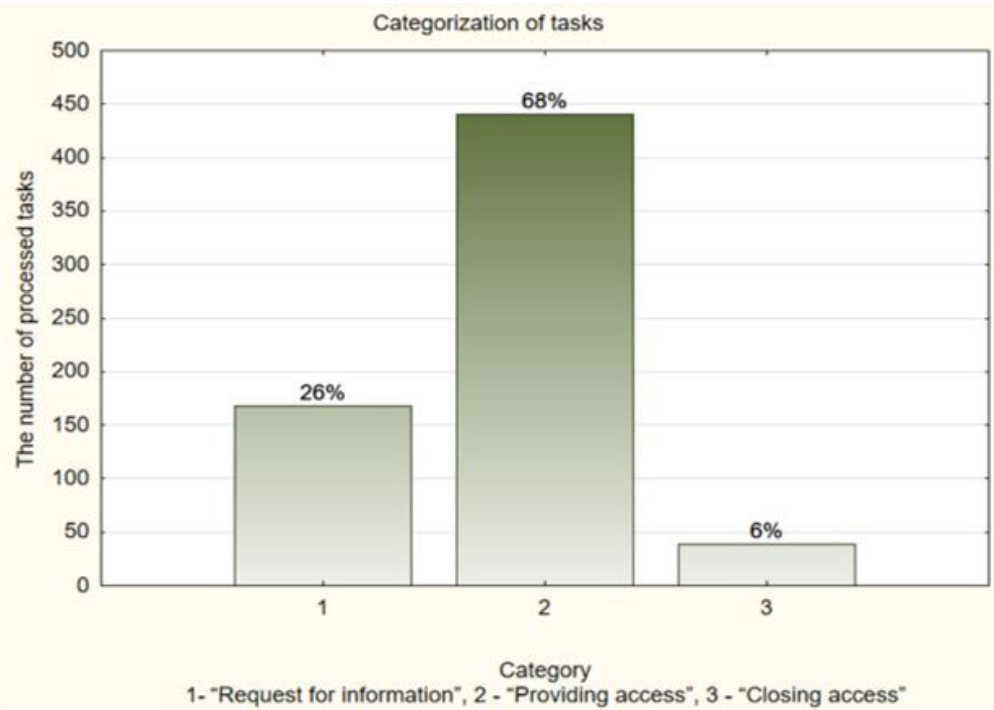

Figure 8: Processed tasks by category 


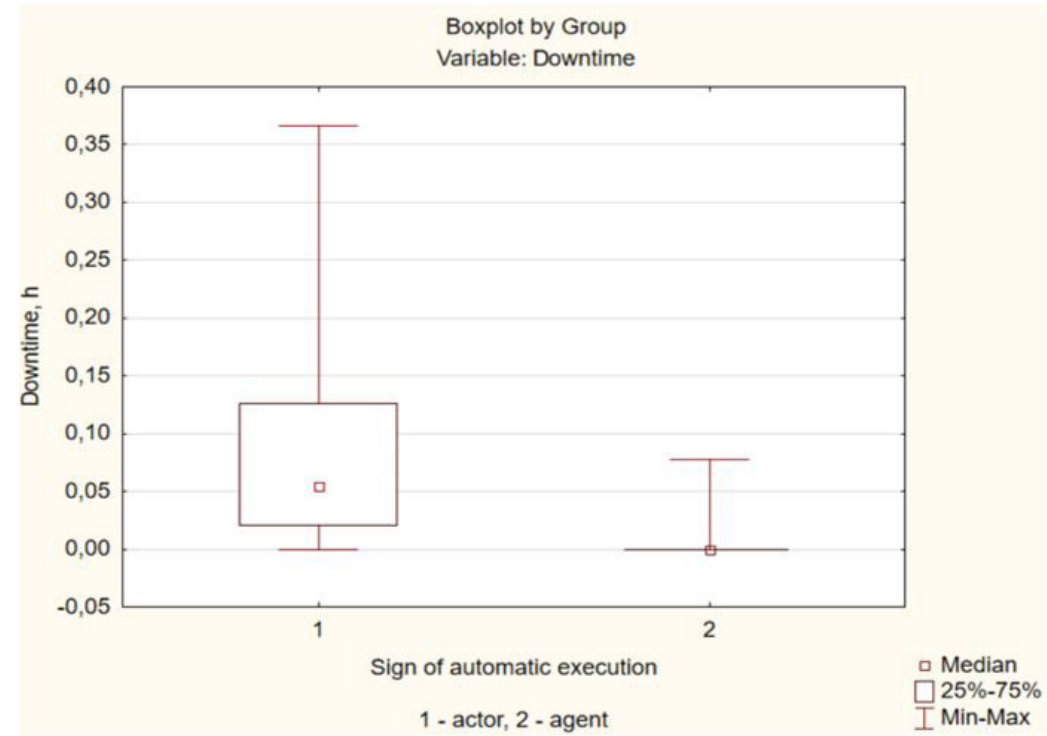

Figure 9: Task waiting time depending on the type of executor

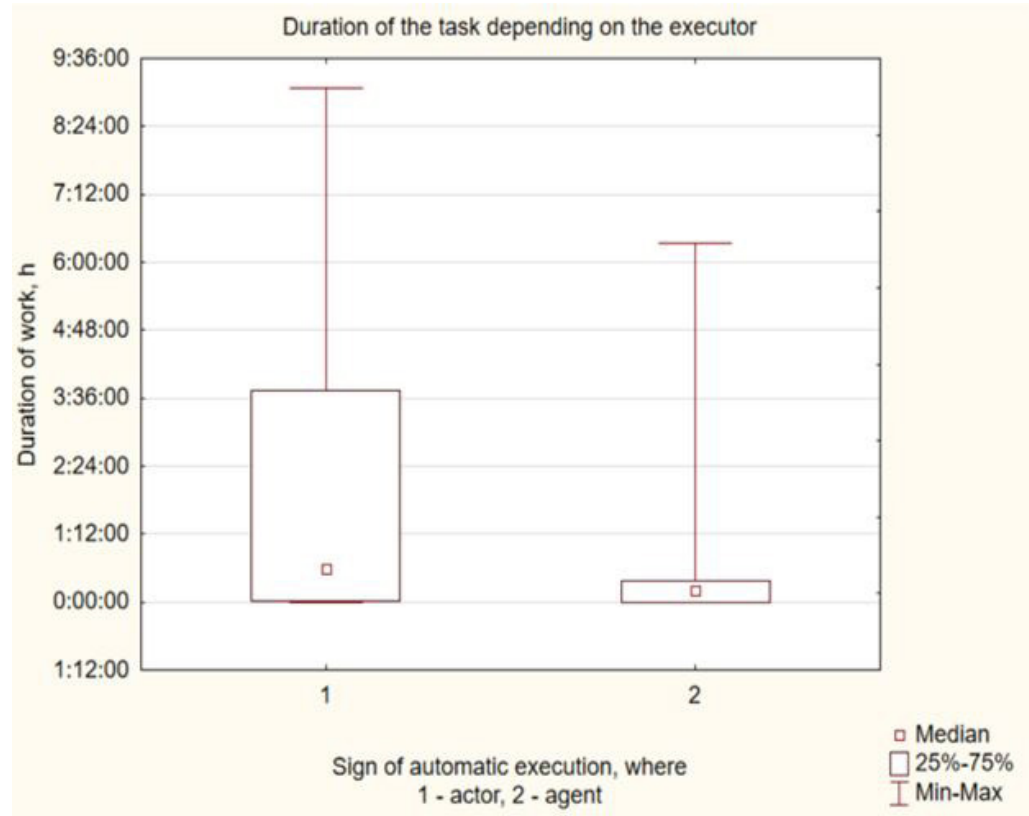

Figure 10: Task duration depending on the executor

Fig. 10 shows that the processing time of tasks is significantly higher for the group 2 agents than for the group 1 actors. For approximately $75 \%$ of the tasks performed by group 2, the processing time does not exceed an hour, while for group 1 this time is up to 3.5 hours. The maximum values for both groups are at a considerable distance from the median, which indicates the emergence of tasks that require significant time for both the agents and the actors.
Based on the average processing time of calls in relation to the number, the average speed of processing calls for the agents and the actors was determined. For an agent it was approximately 3 calls per hour, for an actor approximately 0.3 calls per hour. At the same time, the number of responses from the agent was 67, which corresponds to $14 \%$ of the total number of processed requests for the period. 
Let us evaluate the difference between the two independent samples by the level of the sign of automatic execution (dependence on the executor) using the MannWhitney U-test (see Table 2).

The differences are statistically significant at a high lev$\mathrm{el}$, the indicator $\mathrm{p}<0.05$, i.e. the downtime ( $\mathrm{U}=22088.0$ ) and duration of work $(U=19692.0)$ of the actors is higher than the agents. These results can be logically explained, since the automation and digitalisation were initially designed to optimise and intensify human labour. With the current distribution of tasks, one agent becomes equal to three actors in terms of performance.

As a result of one-factor analysis for the variable duration of tasks, a dependence on the category was revealed, illustrated by Table 3 .

ANOVA analysis of variance was used to determine the differences of execution time spent by the actors for each category of tasks (see Fig. 11). The actors have no failures as they are able to process any task. The tasks of category 1 take longer for successful processing than other categories. Agents have no differences in the average processing time for the tasks of various categories (see Fig. 12).

Table 2: Mann-Whitney U test for the groups of actors and agents

\begin{tabular}{|l|c|c|c|c|c|c|c|}
\hline \multicolumn{1}{|c|}{ Variable } & $\begin{array}{c}\text { Rank Sum for } \\
\text { Actors }\end{array}$ & $\begin{array}{c}\text { Rank Sum for } \\
\text { Agents }\end{array}$ & $\mathbf{U}$ & $\mathbf{Z}$ & Z adjusted & $\begin{array}{c}\text { Valid N } \\
\text { Actors }\end{array}$ & $\begin{array}{c}\text { Valid N } \\
\text { Agents }\end{array}$ \\
\hline Downtime & 71785 & 138491 & 22088 & 8.613 & 9.479 & 166 & 482 \\
\hline $\begin{array}{l}\text { Work dura- } \\
\text { tion }\end{array}$ & 61319 & 106012 & 19692 & 7.821 & 7.969 & 163 & 415 \\
\hline
\end{tabular}

Table 3: Univariate tests of significance for tasks duration

\begin{tabular}{|l|c|c|c|c|}
\hline \multicolumn{1}{|c|}{ Effect } & SS & Degree of freedom & MS & F \\
\hline Intercept & 0.295 & 1 & 0.295 & 80.461 \\
\hline Category & 0.495 & 2 & 0.248 & 67.594 \\
\hline Error & 2.106 & 575 & 0.0037 & \\
\hline
\end{tabular}

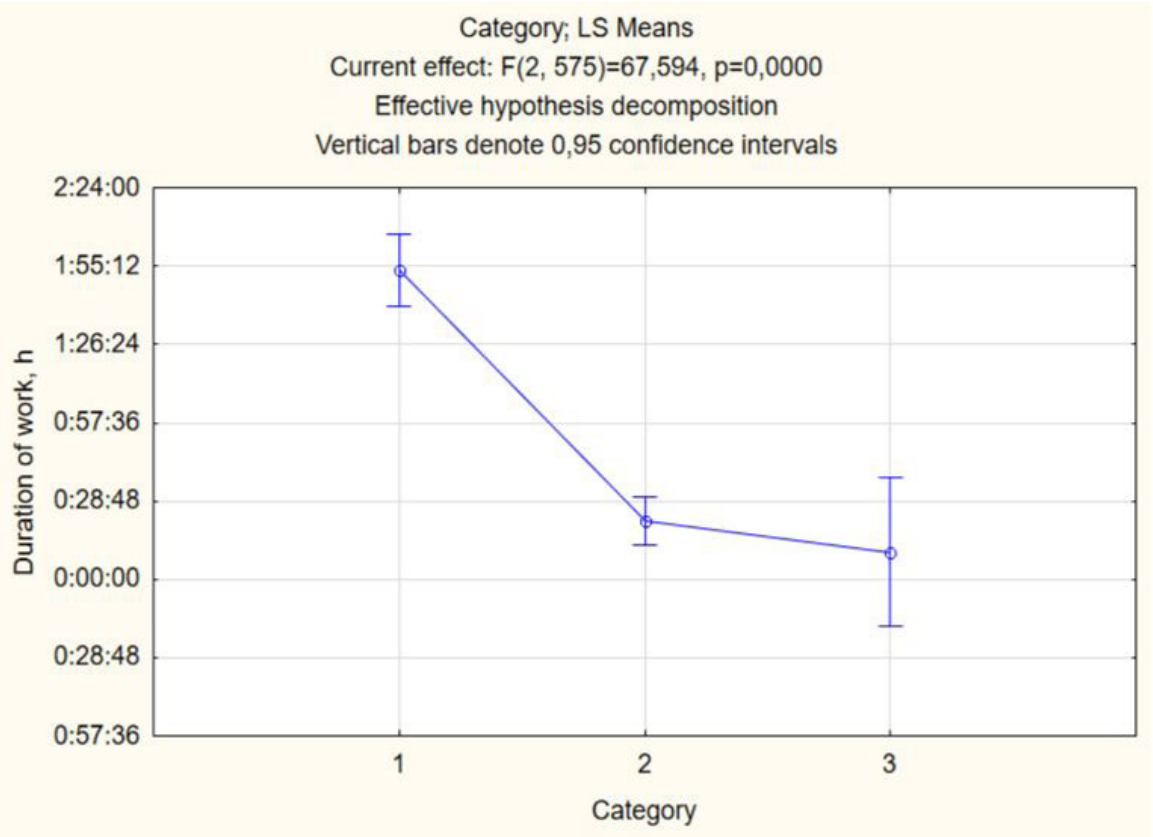

Figure 11: Dependency of tasks processing time by actors on the category 


\section{Category; LS Means}

Current effect: $F(2,412)=1,4828, p=, 22822$

Effective hypothesis decomposition

Vertical bars denote 0,95 confidence intervals

Include condition: $\mathrm{v} 19=2$

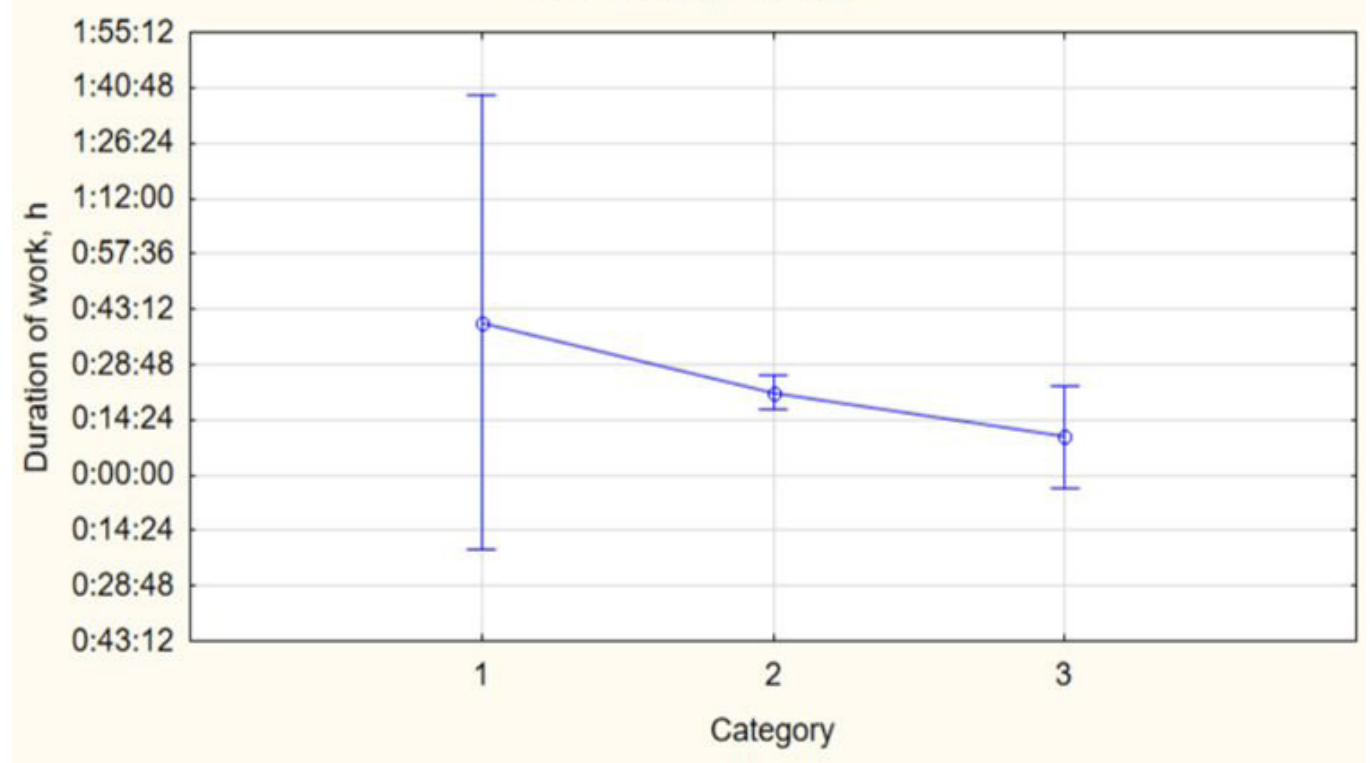

1 - "Request for information", 2 - "Providing access", 3 - "Closing access"

Figure 12: Dependency of tasks processing time by agents on the category

Table 4: Mann-Whitney U test for agents by sucessfully processed tasks and failures

\begin{tabular}{|c|c|c|c|c|c|c|c|c|c|}
\hline Variable & $\begin{array}{c}\text { Rank Sum } \\
\text { Group 1 } \\
\text { Processed }\end{array}$ & $\begin{array}{c}\text { Rank Sum } \\
\text { Group 2 } \\
\text { Failures }\end{array}$ & $\mathbf{U}$ & $\mathbf{Z}$ & $\mathbf{p}$-value & Z adjusted & p-value & $\begin{array}{c}\text { Valid N } \\
\text { Group 1 } \\
\text { Processed }\end{array}$ & $\begin{array}{c}\text { Valid N } \\
\text { Group 2 } \\
\text { Failures }\end{array}$ \\
\hline Category & 100633 & 14807 & 12529 & 1.24 & 0.215 & 2.62 & 0.009 & 413 & 67 \\
\hline
\end{tabular}

For computer agents, statistically significant differences were established between the number of failures and the number of successfully completed tasks by calculating the Mann-Whitney U-test (see Table 4). Despite the high failure rate (14\%) in the amount of 67 requests in group 2, successfully completed tasks still prevail (413 in group 1). At the same time, the efficiency of agents in the direction of reducing the number of failures should be improved.

The results of the statistical analysis showed that, despite the fact that the majority of tasks are processed by agents, and the processing time and waiting time for the agents are less than for the actors, the number of refusals for the agents is greater. This is confirmed by the "Boxplot by Group" plots. The agents are only effective in certain categories of tasks. The actors work less efficiently, but are more stable in solving any type of problem. This conclusion was obtained using the Mann-Whitney $U$ test and ANOVA analysis. 